This is the peer reviewed version of the following article:

Willis, R., Evandrou, M., Pathak, P. \& Khambhaita, P. (2015) 'Problems with measuring satisfaction with social care', Health and Social Care in the Community, first published online 25 March 2015, doi: 10.1111/hsc.12231.

This article may be used for non-commercial purposes in accordance with Wiley Terms and Conditions for self-archiving.

\title{
Problems with measuring satisfaction with social care
}

\section{Authors:}

Rosalind Willis, $\mathrm{PhD}^{1}$

Maria Evandrou, $\mathrm{MSc}^{1}$

Pathik Pathak, $\mathrm{PhD}^{2}$

Priya Khambhaita, $\mathrm{PhD}^{3}$

${ }^{1}$ Centre for Research on Ageing, University of Southampton

${ }^{2}$ Department of Sociology \& Social Policy, University of Southampton

${ }^{3}$ Faculty of Health Sciences, University of Southampton

\section{Disclaimer:}

This paper presents independent research funded by the National Institute for Health Research (NIHR) School for Social Care Research (SSCR). The views expressed are those of the authors and not necessarily those of the SSCR, the NHS, the NIHR or the Department of Health.

\section{Acknowledgements:}

The authors would like to thank all participants who took part in the interviews, together with social services, council, voluntary organisations, and faith groups who helped us design the study and recruit participants. We would also like to thank Christina Nascimento for research assistance with the literature search. 


\title{
Problems with measuring satisfaction with social care
}

\author{
Abstract \\ The measurement of customer satisfaction has become widespread in both health care and social \\ care services, and is informative for performance monitoring and service development. Satisfaction \\ with social care services is routinely measured with a single question on overall satisfaction with care, \\ comprising part of the Adult Social Care Survey. The measurement of satisfaction has been \\ problematised, and existing satisfaction measures are known to be under-theorised. In this article \\ the process of making an evaluation of satisfaction with social care services is first informed by a \\ literature review of the theoretical background, and second examined through qualitative interviews \\ conducted in 2012-13 with 82 service users and family carers in Hampshire, Portsmouth, and \\ Southampton. Participants in this study were from White British and South Asian backgrounds, and \\ the influence of ethnicity in the process of satisfaction evaluation is discussed. The findings show \\ that the majority of participants selected a positive satisfaction rating even though both positive and \\ negative experiences with services were described in their narratives. It is recommended that \\ surveys provide opportunity for service users and family carers to elaborate on their satisfaction \\ ratings. This addition will provide more scope for services to review their strengths and weaknesses.
}

Keywords: satisfaction measurement, social care, evaluation, problem, survey 
What is known about this topic:

- Measurement of satisfaction is popular in health and social care services

- A simple question on satisfaction cannot be assumed to have face validity

- Theoretical models of the satisfaction process have been proposed

What this paper adds:

- Addition of the influences of culture and language to the model of satisfaction process

- A positive satisfaction rating conceals variations in experience of social care services

- Health and social care services should employ qualitative methods to measure satisfaction 


\section{Introduction}

Patient satisfaction measures originated from a need to show value for money and as part of the agenda for patients and service users to have more control over their own care (Edwards \& Staniszewska 2000, Powell et al. 2004). Quantitative surveys for measuring satisfaction are now routinely used in both health and social care services and serve as a means of testing service quality (Powell et al. 2004, Malley et al. 2010). For example, Local Authorities in England carry out User Experience Surveys such as the Adult Social Care Survey (HSCIC 2014). The first item is "Overall how satisfied or dissatisfied are you with the care and support services you receive" rated on a sevenpoint Likert scale from extremely satisfied to extremely dissatisfied. The survey also measures quality of life, drawing on the Adult Social Care Outcomes Toolkit (ASCOT) (Netten 2011). In the current period of funding cuts across the health and social care sectors, satisfaction can be used as a means of justifying the cost of scarce resources. However, the measurement of satisfaction is not as straightforward as it might seem.

\section{Aim}

The focus of this paper is the measurement of satisfaction with social care services. The design of many of the existing patient satisfaction questionnaires has been found wanting (Sitzia 1999). The main criticisms are that they are not sufficiently grounded in theory, that there are logic errors in their underlying assumptions, and that many have not been formally tested for validity and reliability (Edwards \& Staniszewska 2000, Collins \& Nicolson 2002). Further complexities arise when one considers linguistic and cultural differences among the participants (Jeon et al. 2012). In this paper the theoretical literature on the measurement of satisfaction will be reviewed, and examples from a qualitative exploration of satisfaction with adult social care services among people of different ethnic groups will be discussed. These data will be used to support the argument that existing quantitative measures of satisfaction with social care do not accurately capture the views of respondents. 


\section{Context}

The context of social care differs from health care. For example, social care is usually a long-term process, whereas studies of patient satisfaction concentrate on a limited period of treatment (Bauld et al. 2000, Nocon \& Qureshi 1996). In social care there may be no expectation of recovery, a key outcome in healthcare research (Jeon et al. 2012). The care often takes place in the person's own home or care home, bringing a different dynamic than a hospital stay or clinic visit. The power differential is smaller; social care staff are often not 'privileged experts' the way medical staff are (Geron 1998). Therefore, the evaluation of satisfaction with social care may differ in several respects from health care. Nonetheless, many of the problems with satisfaction measurement raised in this article are relevant to both the health care and social care contexts.

\section{Simple model of satisfaction}

Much of the literature on patient satisfaction subscribes to the theory that satisfaction is a simple result of the gap between expectations and experience (Thompson \& Sunol 1995, Taylor 1997, Worthington 2005). This is known as the expectancy-disconfirmation model (Oliver 1980). According to this model, satisfaction is an emotional state which is reached after making an evaluation of whether a person's experience has met, exceeded, or fallen below their original expectations of an ideal experience (see Figure 1).

[Insert Figure 1 about here]

Careful scrutiny of these concepts reveals that the process is much more complicated. Each of these aspects will be defined and explored, and the aspects where ethnicity may have a differential effect will be highlighted. 


\section{Expectations}

Expectations are formed and revised through a cognitive process. People hold expectations about the anticipated experience with the service based on experience and social norms (Hills \& Kitchen 2007). Four subtypes of expectations can be identified: ideal, predicted, normative, and unformed (Thompson \& Sunol 1995). An ideal expectation is a person's most optimistic anticipated experience with a service. A predicted expectation is that person's more realistic view of the service, which is typically lower than their ideal expectation. Normative expectations are influenced by social norms, for example the acceptability of using a particular kind of service. Normative expectations are therefore likely to vary across ethnic or cultural lines (Collins \& Nicolson 2002, Geron 1998). Finally, unformed expectations refers to the state of not having clear thoughts about what will occur in the service experience (Nocon \& Qureshi 1996). A person with unformed expectations may have no prior knowledge or experience with the service in question. Given that many people have no reason to come into contact with social care services, unlike health services, it is likely that many people hold either unformed or normative expectations of social care. Expectations are not fixed, and are subject to revision through experience (Thompson \& Sunol 1995, Carr-Hill 1992).

The simple model of satisfaction assumes that if expectations are met or exceeded, then an individual will be satisfied. However, $98 \%$ of older people using a district nursing service were satisfied, but many had no expectations of the service at all, while others formed expectations only during treatment (Owens \& Batchelor 1996). Therefore, satisfaction cannot have been related solely to fulfilled expectations. Worthington's (2005) review of the literature concludes that the difference between expectation and experience only accounts for $20 \%$ of the variance in satisfaction ratings.

\section{Experience}

Experience refers to the objective characteristics of a particular service, e.g. waiting times and the interaction with staff. Aspects of the experience can be separated into three domains: structure, 
process, and outcome (Donabedian 1980). Structure refers to the organisational aspects of the service, e.g. facilities or policies. Process refers to the way in which the treatment was provided, e.g. staff time keeping. Outcome refers to the result of the treatment, e.g. client is washed and dressed. Within the care experience different aspects, e.g. process rather than outcome, may be important for different people. For example, for some dermatology patients being cured led to high satisfaction, whereas for others being taken seriously by the doctor were more important for satisfaction (Collins \& Nicolson 2002). Even if a person were cured they may report a low level of satisfaction if they had to wait a long time (Hills \& Kitchen 2007). On the other hand, a patient may excuse any process problems experienced (long waiting time) because they see the outcome (being cured) as more important (Hills \& Kitchen 2007, Carr-Hill 1995).

\section{Evaluation}

Evaluation is a subjective judgement of quality or success. This concept introduces an interpretive element to the objective experience, which can vary between individuals (Edwards \& Staniszewska 2000). Conceptual models of the evaluation process are needed to understand individual differences. Many conceptual models have been proposed, from marketing and psychology, which have been adopted by researchers on patient satisfaction. The expectancy-disconfirmation model has already been discussed. The assimilation-contrast model argues that gaps between expectation and experience are either minimised or exaggerated, leading to high or low satisfaction respectively (Anderson 1973). Another model has been influenced by attribution theory, where attribution of blame for a failure in the service can be either external (the service is at fault) or internal (the individual is at fault) (Newsome \& Wright 1999). There may be mitigating factors that allow us to excuse poor treatment and still give a good satisfaction rating (Edwards \& Staniszewska 2000). For example, if the service is not seen as culpable for a bad experience, then the service is not evaluated poorly (Williams et al. 1998). Equity theory (Oliver \& Swan 1989) argues that satisfaction will be higher if a person believes that they have been treated fairly (Thompson \& Sunol 1995), compared 
with other consumers (Williams 1994). Most of the literature on satisfaction tends to focus on the interaction with the service combined with the acceptability of the outcome. However, value for money is an additional factor in the evaluation equation following utility theory (Caruana et al. 2000). The customer's financial outlay for the service compared with an alternative service is weighed up as part of the satisfaction evaluation. England's social care system is means tested, so value in terms of cost to the individual may be relevant to social care service users.

\section{Methodological issues}

\section{Decision to voice}

Much of the patient satisfaction literature has reported high levels of satisfaction, with little variability in the responses (Locker \& Dunt 1978, Edwards \& Staniszewska 2000, Carr-Hill 1992). Even if a person is dissatisfied they might not want to report it. There may be a fear of retribution, such as a service being withdrawn (Edwards \& Staniszewska 2000, Owens \& Batchelor 1996, Bauld et al. 2000, Reed \& Gilleard 1995). Alternatively, it may be seen as unacceptable to complain, e.g. if a person prefers to adopt a traditional patient role characterised by obedience to the medical practitioners (Worthington 2005).

\section{Design of question items}

Some measures of satisfaction employ a single question (known as a global question) asking consumers to rate how satisfied they are on a scale. It requires the consumer to consider all aspects of the service and weigh them up against each other to come to a final decision on overall satisfaction. Other measures of satisfaction ask separately about specific domains of the consumer experience, e.g. about waiting time and interpersonal interactions (Powell et al. 2004). This approach allows the consumer to rate different aspects of the experience independently. Some studies (e.g. Sitzia \& Wood 1997) have found that although global ratings of satisfaction tend to be very high, when asked about different aspects of care patients tend to report lower levels of 
satisfaction. This implies that the global measure does not adequately take into account the various aspects of the care (Chou et al. 2001). Worthington (2005) argues that qualitative methods should be used either to complement or replace survey methods to assess satisfaction.

\section{Biased response sets}

As discussed, surveys of satisfaction with health care or social care tend to show very high satisfaction (Collins \& O'Cathain 2003, Edwards \& Staniszewska 2000). Methodological explanations for such a trend include acquiescent response set (Ware 1978), social desirability bias (Geron 1998), and extreme response set (Bachman \& O'Malley 1984). A person with an acquiescent response set tends to agree with the statements regardless of their topic. A person exhibiting social desirability bias tends to give the answer that they expect the researcher wants to hear (Nocon \& Qureshi 1996). A person with an extreme response set tends to select the most extreme ends of the scale, either the positive or negative extremes. A US study reported that acquiescent responses and extreme responses were more likely among Black participants than White participants (Bachman \& O'Malley 1984). The authors tentatively concluded that 'sub-cultural' linguistic differences may be responsible for the findings, citing linguistic and cultural differences between Southern and Northern USA (Bachman \& O'Malley 1984). Well-designed questionnaires include strategies to identify such biases, including positively and negatively worded items (Sitzia 1999).

\section{Timing of survey administration}

The timing of administering the satisfaction survey is important. Some argue that patient satisfaction surveys should be completed as soon as possible after the treatment episode to maximise accuracy (Jensen et al. 2010). Others argue that the cognitive process of satisfaction takes time, and that if the survey is administered too early a patient will not have had time to go through the process of evaluation (Edwards \& Staniszewska 2000). Respondents completing the Adult Social Care Survey 
are likely to be receiving ongoing care. However, the administration of the survey could occur at a time when an individual is experiencing a problem that could influence their ratings on the survey.

\section{Alternative measures of service outcome}

Satisfaction is not the only concept used to measure outcomes of health or social care services. ASCOT was developed to measure quality of life in social care (Netten et al. 2012). Some of the ASCOT items are measured on Likert scales (e.g. quality of life as a whole, control over daily life), and so could be subject to limitations like biased response sets. However, the ASCOT items have the advantage of focusing on feelings of well-being, rather than on feelings about the service's performance. Therefore, the ASCOT items could be less likely to be influenced by variations in expectations of services.

Discrete Choice Experiments (DCEs) are a means of gathering data on preferences through hypothetical choices (Ryan 2004). The method allows participants to indicate the aspects of care that are most important to them, e.g. short waiting time or continuity of care. Meeting a person's preferences would theoretically lead to greater satisfaction, drawing on ideal expectations. However, DCEs represent hypothetical preferences, and do not necessarily reflect satisfaction judgements. The link between DCEs and satisfaction with social care is a potential area for future research to explore, particularly as it offers scope for making comparisons between different groups of service users.

A further patient feedback technique that has gained popularity in the NHS in recent years is the Friends and Family Test (FFT), where patients are asked if they would recommend the service to others. It goes beyond an evaluation of satisfaction, and implies a sense of loyalty through actively promoting the service. The FFT has been criticised, e.g. that the rating does not match experiences (Graham \& MacCormick 2012). However, the guidance for the FFT recommends providing an 
opportunity for patients to give follow-up answers (DH 2012), which could potentially overcome some of the methodological problems.

\section{Revised model of satisfaction process}

The discussion of the theoretical and methodological issues in satisfaction measurement demonstrates that the simple model of satisfaction is inadequate. Hence, a new model of the satisfaction process incorporating features of the issues discussed appears in Figure 2.

[Insert Figure 2 about here]

\section{Research question}

This paper utilises qualitative methodology to examine service users' and carers' discussions of satisfaction with social care services, in order to ascertain whether a global Likert scale question on satisfaction adequately captured their experience.

\section{Methodology}

The data in this paper come from a qualitative study exploring satisfaction with adult social care services among people from different ethnic groups. The study was funded by the National Institute for Health Research (NIHR) School for Social Care Research (SSCR) with the aim of answering the research question as to why people from minority ethnic groups have reported lower satisfaction with social care services compared with the White population in England in past User Experience Surveys (e.g. HSCIC 2013).

In order to understand the determinants of satisfaction and dissatisfaction, in-depth individual interviews were conducted with adult service users and informal carers from White British and South Asian ethnic groups in three Local Authority regions: Hampshire, Portsmouth, and Southampton. Purposive sampling was adopted to recruit participants from the two target ethnic 
groups, and was supplemented with snowball sampling (Bryman 2012). Service users and carers were recruited through several means. First, invitation letters were posted by Local Authority Social Services departments to service users and carers. Second, gatekeepers of interest groups were approached for advice on how to recruit participants. Permission was given for the research team to visit temples, mosques, churches, carers groups, social groups, etc, in order to introduce the project to potential participants. Finally, people who had taken part in the study were asked if they would mind passing on the researchers' details to their friends and family members.

Interviews were conducted in English, Hindi, or Gujarati, depending on the preference of the participant. Ethical approval for the research was obtained from the National Social Care Research Ethics Committee, and research governance approval was obtained from the three Local Authorities involved. Informed consent was given by all participants, either in written or recorded verbal form.

The interviews were semi-structured, with mostly open-ended questions about experiences using social services. In addition, there was one closed-ended question to ask about their satisfaction rating, following the satisfaction question in the national surveys. Interviews were recorded and transcribed, and translated where necessary. Data were analysed using thematic analysis (Braun \& Clarke 2006) and the principles of open coding, constant comparison, negative case analysis, and memo writing (Mason 2002). In addition, some a-priori codes derived from the literature review were used. Data were not forced into these a-priori codes, instead they were used as reminders to look for instances of theoretical importance in the data. The NVivo 10 software program was used to facilitate data storage, categorisation, and retrieval. Two coders independently coded the transcripts, and compared their coding. Codes and themes were developed through discussion with the project team, and checked by returning to the transcripts. The primary research question is answered in a separate article. This paper focuses on how participants spoke about the concept of satisfaction itself, and their struggles to reconcile their myriad experiences with a single rating. 


\section{Results}

Eighty-two participants were interviewed, comprising 46 service users (SU) and 36 carers (39 South Asian (SA) and 43 White British (WB) participants). Their ages ranged from 18-90, with the majority aged over 65. Services used included domiciliary care, residential care, day centres, and carers' groups, among others.

\section{Satisfaction rating}

During the interviews participants were asked to rate their satisfaction with the services using the same seven-point Likert scale as used in the User Experience Surveys. Consistent with previous research, the majority of participants gave a positive satisfaction rating. Only 11 out of 82 chose a negative satisfaction rating (six South Asian and five White British participants).

Although the majority gave a positive satisfaction rating, very few participants were happy with every aspect of their experience. It is of interest to examine how the participants justified their positive satisfaction rating despite their negative experiences.

Some participants qualified their satisfaction rating by omitting the dissatisfactory aspect of care. These quotes show that the negative aspects are minimised or dismissed as 'minor' or 'silly':

Very satisfied ... A bit cross at the length of time it took. But, other than that, you know. (Carer 02, WB)

But, otherwise [not enough staff at the day centre], they were excellent, I wouldn't, wouldn't decry them at all. It was just silly little things, you know, but they're only minor irritations, they're not major problems so we don't worry about them. (SU 04, WB)

Some participants were willing to disregard even potentially serious issues when making their satisfaction judgement: 
I would say that apart from that one incident [medication mistake while in respite care] apart from that one incident, I was totally satisfied there, very satisfied, yes. (SU 39, WB)

Some participants cited mitigating factors to justify the positive satisfaction rating, despite experiencing problems. The quote shows that the service user did not include the lengthy wait for support in her satisfaction evaluation, and justified this decision by explaining that her social worker was busy and that her own case was complex. The interpersonal interactions were good, so the participant found a way to excuse the social worker from blame:

SU 31 SA: She [my social worker] was fantastic, so I was extremely satisfied with her, and I felt that she heard me, and I felt that she got through the whole process as quickly and as effortlessly as possible given the situation. Interviewer: So 'given the situation', do you mean there were constraints? SU 31 SA: Or should I say given the nature of her workload and the things that I was going through, so really it was a case of us being patient with each other yet having a good communication in between. You know, it took about, it took almost eight months for me to get my support. (SU 31, SA)

\section{Difficulties in selecting a satisfaction rating}

Three participants discussed the difficulty of settling on a satisfaction rating when their experiences had been varied. Some asked the interviewer how they should resolve this dilemma in order to answer the question 'correctly':

My main thing is that what they said that they were going to do, they didn't do, and it's been over a year. I am not satisfied with that but with everything else I would say that I am very satisfied. So which one should I tick? (laughs) (SU 14, SA)

Another difficulty with the satisfaction question is that it doesn't allow for change over time. Such changes could relate to, for example, staffing or eligibility criteria. One participant put the difficulty very clearly, when he discussed how satisfaction is 'temporal', and depends on the circumstances at the time of asking: 
So that's when it kind of went from very satisfied - well it went from extremely satisfied when she had two guys that she knew very well who were there for most of the time ... but then like I said, there was a change in provider by the council ... and when that happened it started to become a little bit fragmented and disjointed in terms of consistency of who came to see them and the times which they came to see them. So she kind of slipped towards the other end of the scale [of satisfaction]. So I can't really give you like one definitive [answer]. It's more temporal. (Carer 33, WB)

\section{The meaning of 'quite satisfied'}

The meaning of the Likert scale categories was raised in some of the interviews. Participants differed in their understanding of what 'quite satisfied' means. In the next quote the participant gave a rating of quite satisfied even though some of the staff were patronising towards her husband, the care recipient. This raises the question of how poor the experience needs to be in order to give a negative satisfaction rating:

Interviewer: I'd like to ask you to rate how satisfied you are with the services that you had for your husband. So how satisfied from a scale of extremely satisfied ... [shows flashcard with Likert scale]

Carer 29 WB: [interrupts] Probably quite satisfied, yes.

Interviewer: So quite satisfied with the carers that came in to help your husband?

Carer 29 WB: Yes.

Interviewer: So why would you say quite satisfied?

Carer 29 WB: Well as I said they had such varied, and some would come in and would speak over my husband, and I had to say, well he's there, he can hear, he knows everything that's going on. You had to sort of stop them speaking ... as if he wasn't there, or treating him just like an object instead of a person. (Carer 29, WB)

The next participant defines 'quite satisfied' as 'alright' but 'nothing brilliant'. In other words, the care was adequate. This differs from the previous quote where the care received clearly had negative aspects:

Interviewer: Ok, so if I show you this scale [shows flashcard with Likert scale], ok, it's from extremely satisfied to extremely dissatisfied, where would you put yourself on that scale? SU 28 SA: I'd put them, you know, like, quite satisfied. Interviewer: Quite satisfied? Ok. SU 28 SA: There's nothing brilliant about it but it's quite alright. (SU 28, SA) 
participant. In this example 'quite satisfied' can have a different meaning to the same individual depending on the intonation. This difference in intonation could explain how the differing experiences of the two previous participants led to the same satisfaction rating:

[Discussing why chose 'Quite Satisfied'] It's better staffed, a better building, much more space, better managed. [pause] Actually, when you say 'quite' it depends on your intonation, doesn't it? [Said rapidly] "Quite satisfied", yes, that means everything's okay. [Emphasises first word] "Quite satisfied" means, Mmmm [with rising \& falling tone, and tilts hand from one side to the other indicating some things good some things bad], so mine would be on the [said rapidly] "Quite satisfied" thing. (Carer 21, WB)

If intonation can make such a difference in meaning to a native English speaker, then the complexity introduced when answering the satisfaction question in one's second language must be a different order of magnitude. A further consideration is the familiarity of rating scales:

Hmmm, I suppose if you said to somebody 'Would you mark this seven out of ten, nine out of ten?' I know my mum would struggle with that. Perhaps because they've never been, most of those people [parents' generation, first generation migrants, English as a second language] possibly wouldn't have had umm exposure to that kind of language. (Carer 26, SA)

Additional aspects raised by participants included preferences for face-to-face interviews versus impersonal questionnaires, the importance of the questionnaire being available in translated versions, and concern about retribution leading to low response rates.

\section{Discussion}

Few participants were entirely happy with their social services experience. Despite this, we found a similar bias toward positive satisfaction ratings in our interviews as reported in prior research (Collins \& O'Cathain 2003). The global question of satisfaction requires respondents to reduce their entire history of interaction with a service to a single rating. This posed problems for some of our participants, for example if some aspects of the experience had been good but other aspects had been poor they could not settle on a rating. The decision making process described by many 
participants in the present study indicated that they tended to use their best example of experience from the service in order to make the satisfaction rating, while their worst experiences were minimised, possibly a form of assimilation-contrast. The satisfaction rating that results from such a process is unlikely to be informative for social services as it cannot be used to identify aspects for service improvement. An alternative solution would be to ask participants to rate their satisfaction with different domains of the service, e.g. evaluating structure, process, and outcome separately (Powell et al. 2004).

A further improvement would be to provide an opportunity for respondents to convey more detail about their experience (Worthington 2005). This would allow participants to describe their reasons for satisfaction or dissatisfaction. It would also enable the temporal aspect of satisfaction to be assessed. For example, a respondent could describe how an initially unsatisfactory situation was resolved leading to satisfaction. Such an opportunity could be afforded through having free text spaces after each satisfaction question for optional elaborations. An alternative approach would be to conduct individual in-depth interviews with service users and carers in order to ask about their experience, much as has been done in the present study. The advantage of this approach is that the services will gain a clearer understanding of their strengths and weaknesses. The disadvantage of course is that such an approach is not as cost-effective as postal surveys (Geron 1998).

There did not seem to be an ethnic group difference in satisfaction rating, contrary to the User Experience Survey findings (HSCIC 2013). Both ethnic groups in our study were dissatisfied with similar issues, e.g. long waiting times, suggesting that the evaluation of these aspects is not influenced by ethnic differences. The aspects where the South Asian participants were different from the White British participants mainly included language. South Asian participants discussed the need for the questionnaires to be translated into relevant languages, or for a translator to assist the service user to complete the questionnaire. It is of interest to note that the two people who 
mentioned fear of retribution for making a negative evaluation were South Asian. This is not to suggest that South Asian service users are more likely to feel this way; the sampling approach adopted for this study makes such generalisations unwise. Rather, the people who consented to take part in the interview are likely to have a more compliant tendency, and most of those who feared retribution from taking part in research would not have consented. Therefore, it is likely that some people will hold this fear whereas others will not, regardless of ethnicity.

The content of participants' discussions of satisfaction indicates what they considered relevant to consider in their evaluations. Most of the participants discussed the process domain, including the interpersonal skills of staff and consistency. Fewer participants focused on issues of structure, e.g. the fabric of the building. The third domain, outcome, came under discussion as a reason for dissatisfaction, particularly when the outcome was that participants' care needs were not met. Among the mitigating factors mentioned was workload (structure), which was deployed to excuse perceived failings in the staff so that their interpersonal skills (process) could be given a higher priority when making the satisfaction rating. Most of the satisfaction instruments reviewed by Jeon and colleagues (Jeon et al. 2012) were focused on interpersonal aspects of care rather than the organisational aspects. The present study's findings support the design of those instruments by demonstrating that when given an opportunity to freely discuss the reasons for their satisfaction rating, most participants tended to focus more on the domain of process and less on the other two. However, it is still important to measure the other two as they can be useful for identifying areas for service improvement.

As already stated, the results of this qualitative study should not be generalised to a larger population. However, the findings from this sample of service users and carers are illuminating for understanding the thought processes involved when responding to satisfaction questionnaires. 
Our findings support the theory that when making a satisfaction rating, some people will excuse a problem in the social care process as long as the desired outcome was achieved (Hills \& Kitchen 2007). However, that does not mean that the problematic aspects do not need to be addressed. Therefore, we argue that the satisfaction rating from the User Experience Surveys is not an accurate reflection of the full service user experience. On balance, the evidence shows that domain questions are preferable to a global question on satisfaction. Furthermore, the surveys should provide opportunities for respondents to convey more detail, e.g. through open ended questions. Finally, future research could explore DCEs and the theoretical relationship between preferences, expectations, and satisfaction. 


\section{References}

Anderson, R. (1973) Consumer dissatisfaction: The effect of disconfirmation expectancy on perceived product performance. Journal of Marketing Research, 10 (1), 38-44.

Bachman, J. G. \& O'Malley, P. M. (1984) Yea-saying, nay-saying, and going to extremes: Black-White differences in response styles. Public Opinion Quarterly, 48 (2), 491-509.

Bauld, L., Chesterman, J. \& Judge, K. (2000) Measuring satisfaction with social care amongst older service users: Issues from the literature. Health and Social Care in the Community, 8 (5), 316324.

Braun, V. \& Clarke, V. (2006) Using thematic analysis in psychology. Qualitative Research in Psychology, 3 (2), 77-101.

Bryman, A. (2012) Social Research Methods. Oxford University Press, Oxford.

Carr-Hill, R. (1992) The measurement of patient satisfaction. Journal of Public Health Medicine, 14 (3), 236-249.

Carr-Hill, R. (1995) Measurement of user satisfaction. IN G. Wilson (Ed.) Community Care: Asking the User, pp.16-36. Chapman \& Hall, London.

Caruana, A., Money, A. H. \& Berthon, P. R. (2000) Service quality and satisfaction - the moderating role of value. European Journal of Marketing, 34 (11/12), 1338-1352.

Chou, S., Boldy, D. \& Lee, A. (2001) Measuring Resident Satisfaction in Residential Aged Care. The Gerontologist, 41 (5), 623 - 631.

Collins, K. \& Nicolson, P. (2002) The meaning of 'satisfaction' for people with dermatological problems: Reassessing approaches to qualitative health psychology research. Journal of Health Psychology, 7 (5), 615-629.

Collins, K. \& O'Cathain, A. (2003) The continuum of patient satisfaction - from satisfied to very satisfied. Social Science \& Medicine, 57 2465-2470.

DH (2012) The NHS Friends and Family Test: Implementation Guidance. Department of Health, Leeds.

Donabedian, A. (1980) Explorations in Quality Assessment and Monitoring Volume 1: The Definition of Quality and Approaches to its Assessment. Health Administration Press, Ann Arbor.

Edwards, C. \& Staniszewska, S. (2000) Accessing the user's perspective. Health and Social Care in the Community, 8 (6), 417-424.

Geron, S. M. (1998) Assessing the satisfaction of older adults with long-term care services: Measurement and design challenges for social work. Research on Social Work Practice, 8 (1), $103-119$.

Graham, C. \& MacCormick, S. (2012) Overarching questions for patient surveys: Development report for the Care Quality Commission (CQC). Picker Institute Europe, Oxford.

Hills, R. \& Kitchen, S. (2007) Toward a theory of patient satisfaction with physiotherapy: Exploring the concept of satisfaction. Physiotherapy Theory and Practice, 23 (5), 253-254.

HSCIC (2013) Personal Social Services Adult Social Care Survey, England - 2012-13, Final release. HSCIC, Leeds.

HSCIC (2014) Personal Social Services Adult Social Care Survey, England. Information and guidance for the 2014-15 survey year. Health and Social Care Information Centre, Leeds.

Jensen, H., Ammentorp, J. \& Kofoed, P. (2010) User satisfaction is influenced by the interval between a health care service and the assessment of the service. Social Science \& Medicine, 70 (12), 1882 - 1887.

Jeon, Y., Fethney, J. \& Ludford, I. (2012) Measuring Client Satisfaction in Residential Aged Care Settings: A Narrative Review of Instruments. The Internet Journal of Healthcare Administration, 8 (1), 1-10. 
Locker, D. \& Dunt, D. (1978) Theoretical and methodological issues in sociological studies of consumer satisfaction with medical care. Social Science \& Medicine, 12 283-292.

Malley, J., Caiels, J., Fox, D., et al. (2010) A report on the development studies for the National Social Care User Experience Survey. PSSRU Discussion Paper No. 2721. Personal Social Services Research Unit, University of Kent, Canterbury.

Mason, J. (2002) Qualitative Researching. Sage, London.

Netten, A. (2011) Overview of outcome measurement for adults using social care services and support. Methods Review 6. NIHR School for Social Care Research, London.

Netten, A., Burge, P., Malley, J., et al. (2012) Outcomes of social care for adults: developing a preference-weighted measure. Health Technology Assessment, 16 (16), 1-165.

Newsome, P. R. H. \& Wright, G. H. (1999) A review of patient satisfaction: 1. Concepts of satisfaction. British Dental Journal, 186 (4), 161-165.

Nocon, A. \& Qureshi, H. (1996) Outcomes of Community Care for Users and Carers: A Social Services Perspective. Open University Press, Buckingham.

Oliver, R. (1980) A cognitive model of the antecedents and consequences of satisfaction decisions. Journal of Marketing Research, 17 (4), 460-469.

Oliver, R. \& Swan, J. E. (1989) Equity and disconfirmation perceptions as influences on merchant and product satisfaction. Journal of Consumer Research, 16 (3), 372-383.

Owens, D. J. \& Batchelor, C. (1996) Patient satisfaction and the elderly. Social Science \& Medicine, 42 (11), 1483-1491.

Powell, R. A., Holloway, F., Lee, J. \& Sitzia, J. (2004) Satisfaction research and the uncrowned king: Challenges and future directions. Journal of Mental Health, 13 (1), 11 - 20.

Reed, R. \& Gilleard, C. (1995) Elderly patients' satisfaction with a community nursing service. IN G. Wilson (Ed.) Community Care: Asking the User, 111-125. Chapman \& Hall, London.

Ryan, M. (2004) Discrete choice experiments in health care. British Medical Journal, 328 360-361.

Sitzia, J. (1999) How valid and reliable are patient satisfaction data? An analysis of 195 studies. International Journal for Quality in Health Care, 11 (4), 319 - 328.

Sitzia, J. \& Wood, N. (1997) Patient satisfaction: A review of issues and concepts. Social Science \& Medicine, 45 (12), 1829-1843.

Taylor, K. A. (1997) A regret theory approach to assessing consumer satisfaction. Marketing Letters, 8 (2), 229-238.

Thompson, A. G. H. \& Sunol, R. (1995) Expectations as determinants of patient satisfaction: Concepts, theory and evidence. International Journal for Quality in Health Care, 7 (2), 127-141.

Ware, J. E. J. (1978) Effects of acquiescent response set on patient satisfaction ratings. Medical Care, 16 (4), 327-336.

Williams, B. (1994) Patient satisfaction: A valid concept? Social Science \& Medicine, 38 (4), 509-516.

Williams, B., Coyle, J. \& Healy, D. (1998) The meaning of patient satisfaction: An explanation of high reported levels. Social Science \& Medicine, 47 (9), 1351-1359.

Worthington, C. (2005) Patient satisfaction with health care: Recent theoretical developments and implications for evaluation practice. The Canadian Journal of Program Evaluation, 20 (3), 41 63. 
Figure 1: Simple model of the satisfaction process

Expectations $\Rightarrow \quad$ Experience $\Rightarrow \quad$ Evaluation $\Rightarrow \quad$ Satisfaction

Source: authors' review of the literature 
Figure 2: More complex model of the satisfaction process

Feedback loop: Experiences inform expectations of future care

\begin{tabular}{|lllll}
\multicolumn{1}{l|}{} & & & \\
\hline Expectations $\Rightarrow$ & Experience $\Rightarrow$ & Evaluation $\Rightarrow$ & Satisfaction $\Rightarrow$ & Decision to Voice \\
Ideal & Structure & Disconfirmation & Feeling content & Fear of retribution \\
Predicted & Process & Attributions & Social desirability \\
Normative & Outcome & Assimilation-contrast & Acquiescent response set \\
Unformed & Equity & Extreme response set \\
& & Utility &
\end{tabular}

Source: authors' review of the literature 